\title{
Sialendoscopy and Minimally Invasive Salivary Gland Surgery
}

\section{Preface}

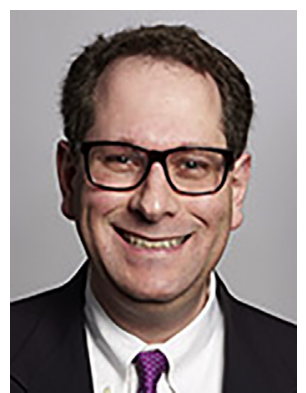

Michael D. Turner, DDS, MD, FACS

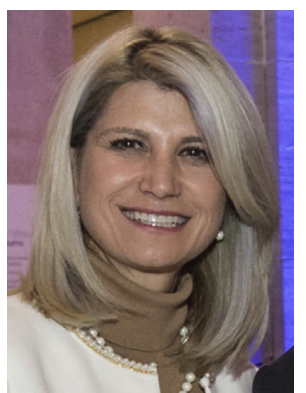

Maria J. Troulis, DDS, MSc, FACS

Editors

Minimally invasive surgery provides a decrease in morbidity in most surgeries, with shorter hospital stays and a quicker recovery time for patients. Many surgical disciplines have been driven by their patients' desires and requests to embrace minimally invasive surgical alternatives. Pioneers of sialendoscopy, Drs Katz, Nahlieli, Marchal, Iro, and McGurk found it difficult to accept submandibular gland excision and parotidectomy for the treatment of obstructive salivary gland disease. With the improvement in technology, continuing, and resident education, a paradigm shift for the management of salivary gland stones and other salivary gland diseases has occurred globally. This technology, even in its current state, eliminates the use of large facial incisions and minimizes the risk to the nerves of the face and mouth. It has been a 20 -year journey to modify and improve these procedures and it still continues to do so.

It has been a team effort to complete this Atlas of the Oral and Maxillofacial Surgery Clinics of North America: two editors, a multitude of expert clinicians, artists, and a patient publisher. We are grateful to the support of our families: M.D.T.: Susie, Asher, and Danielle; M.J.T.: Michael, Tyler, and Connor. Also, we are grateful to our academic institutions, which support and promote innovation. We are grateful to our wonderful contributors, who gave their time and effort to create this publication. We are also grateful to the publisher, Elsevier, in giving us this opportunity to create this work. We would also like to thank the people at Karl Storz Endoscopy and Cook Medical, who, without their support of this technique and the development of the technology and products, this procedure would not exist. A thank you to Ms Erin Holderman, of the education department at Karl Storz Endoscopy, who drove the acceptance of this technique in the United States by constantly supporting the education and acceptance of the procedure by practicing surgeons and residents. We would also like to thank Oded Nahlieli, who introduced and taught us this technique, and our mentors (M.J.T.: L. Kaban) and (M.D.T.: Daniel Buchbinder), who encouraged us to pursue unknown territory and learn and be better.

Certainly, this work would not be possible without our funding agencies, NIH (K23 DE 14070-01), Hanson Foundation (Boston, MA), the Walter C. Guralnick Research Fund (Haseotes-Bentas Foundation, Boston, MA), the MGHOMFS Education/Research Fund (Boston, MA), the Lynn Foundation (Scottsdale, AZ), and Le Fondation Bertarelli (Switzerland) and the support of Karl Storz Endoscopy and Cook Medical Corporations.

Finally, being in academic Medical Centers, we hope that residents, whose curiosity make us be better teachers and innovators, will appreciate the new technology and the new innovations and hopefully adopt them into their practice and continue to improve upon them.

We hope you enjoy this Atlas of the Oral and Maxillofacial Surgery Clinics of North America as much as we enjoyed creating it, and we hope you find it useful in your surgical practice.

Michael D. Turner, DDS, MD, FACS Icahn School of Medicine at Mount Sinai 10 Union Square East Suite 5B

New York, NY 10003, USA

Maria J. Troulis, DDS, MSc, FACS Oral and Maxillofacial Surgery

Massachusetts General Hospital Oral and Maxillofacial Surgery Harvard School of Dental Medicine Warren 1201

55 Fruit Street

Boston, MA 02114, USA

E-mail addresses: mturnerddsmd@gmail.com (M.D. Turner) mtroulis@partners.org (M.J. Troulis) 